\title{
FLOPROS: an evolving global database of flood protection standards
}

\author{
Paolo Scussolini ${ }^{1}$, Jeroen C. J. H. Aerts ${ }^{1}$, Brenden Jongman ${ }^{1}$, Laurens M. Bouwer ${ }^{2}$, Hessel C. Winsemius ${ }^{2}$, \\ Hans de Moel $^{1}$, and Philip J. Ward ${ }^{1}$ \\ ${ }^{1}$ Institute for Environmental Studies, Vrije Universiteit Amsterdam, De Boelelaan 1087, \\ 1081 HV Amsterdam, the Netherlands \\ ${ }^{2}$ Deltares, P.O. Box 177, 2600 MH Delft, the Netherlands \\ Correspondence to: Paolo Scussolini (paolo.scussolini@vu.nl)
}

Received: 28 October 2015 - Published in Nat. Hazards Earth Syst. Sci. Discuss.: 7 December 2015

Revised: 24 March 2016 - Accepted: 8 April 2016 - Published: 3 May 2016

\begin{abstract}
With projected changes in climate, population and socioeconomic activity located in flood-prone areas, the global assessment of flood risk is essential to inform climate change policy and disaster risk management. Whilst global flood risk models exist for this purpose, the accuracy of their results is greatly limited by the lack of information on the current standard of protection to floods, with studies either neglecting this aspect or resorting to crude assumptions. Here we present a first global database of FLOod PROtection Standards, FLOPROS, which comprises information in the form of the flood return period associated with protection measures, at different spatial scales. FLOPROS comprises three layers of information, and combines them into one consistent database. The design layer contains empirical information about the actual standard of existing protection already in place; the policy layer contains information on protection standards from policy regulations; and the model layer uses a validated modelling approach to calculate protection standards. The policy layer and the model layer can be considered adequate proxies for actual protection standards included in the design layer, and serve to increase the spatial coverage of the database. Based on this first version of FLOPROS, we suggest a number of strategies to further extend and increase the resolution of the database. Moreover, as the database is intended to be continually updated, while flood protection standards are changing with new interventions, FLOPROS requires input from the flood risk community. We therefore invite researchers and practitioners to contribute information to this evolving database by corresponding to the authors.
\end{abstract}

\section{Introduction and rationale}

A large portion of the world's population is prone to flooding. About 0.8 billion people and USD 50 trillion are exposed to a 1-in-100-years river flood event (Jongman et al., 2012; Kundzewicz et al., 2013), and 40 million people and USD 3 trillion are exposed to coastal floods in the world's main port cities (Hanson et al., 2011). River floods alone resulted in direct economic losses exceeding USD 1 trillion between 1980 and 2013, and more than 220000 fatalities (Munich Re, 2013). Future damaging impacts of floods are projected to increase in many parts of the world, by increasing encroachment of population and economic activities on river and coastal plains resulting from socioeconomic growth, as well as by projected increases in intense precipitation due to climate change (Min et al., 2011; IPCC, 2014; Winsemius et al., 2016). Estimating the present and future risk of floods is therefore critical in the ongoing discourse on the impacts of climate change: to motivate climate change mitigation policy; to identify hotspots of risk; and to plan investments in adaptation, on a range of spatial and decision-making domains, such as water management, agriculture, risk management and risk financing (Hall et al., 2012).

The last decade has seen great advances in large-scale modelling of flood hazard (Milly et al., 2002; Pappenberger et al., 2012; Rojas et al., 2012; Dankers et al., 2014), exposure (Jongman et al., 2012; Hanson et al., 2011), vulnerability (Jongman et al., 2015), risk (Nicholls, 2004; Hirabayashi et al., 2013; Winsemius et al., 2013, 2016; Rojas et al., 2013; Ward et al., 2013, 2014; Hinkel et al., 2013, 2014; Jongman 
et al., 2014; Alfieri et al., 2015), and other indicators of flood risk (Arnell and Gosling, 2014). In parallel, tools have been devised to make this type of knowledge accessible to a vast range of users (e.g. the Global Flood Analyzer ${ }^{1}$ ). Also at the smaller scale, assessments of flood risk are becoming more sophisticated (te Linde et al., 2011; Merz et al., 2014; Miller et al., 2015; de Moel et al., 2015).

The results from the current generation of large-scale flood risk models, however, remain highly uncertain (Ward et al., 2015). Typically, these models calculate damage for floods with several return periods, and integrate this damage in their annual likelihood of occurrence to estimate the annual expected damage. Because information on flood protection standards for most places in the world is severely limited, most current assessments either assume highly simplified flood protection standards, or assume no protection. Therefore, the integration of damage takes place along the whole spectrum of return periods, including damage of frequent (i.e. high return period) flood events that in reality are often prevented by existing protection. This results in a systematic overestimation of hazard, and greatly limits the accuracy of the computation of actual flood risk (e.g. IPCC, 2014; Hinkel et al., 2014). For example, Ward et al. (2013), using a global river flood risk model, found that the expected annual damage, assuming that all areas were protected against a flood with a return period of only 5 years, was about $40 \%$ lower than in the absence of protection.

In this dearth of information on protection, researchers have devised solutions to circumvent the problem by assuming different standards of flood protection for different income regions across the globe (e.g. Mokrech et al., 2015; Sadoff et al., 2015; PBL, 2014). On the other hand, Jongman et al (2014) developed estimates of flood protection covering all river basins in the European Union, using a risk-based approach (i.e. assigning higher protection values to areas of higher risk), making use of a number of available empirical data points. They then included these protection estimates in a probabilistic continental flood risk model.

While these synthetic estimations of flood protection standards indeed lead to improved results of flood damage simulations, quantifications of protection standards have not been extended beyond Europe, and the required empirical information available on protection standards is still extremely limited (e.g. Hall, 2014; de Moel et al., 2015). Some efforts, however, have been made to improve this empirical data availability. Linham et al. (2010) compiled a global list of adaptation standards for 32 coastal cities from "reports, email surveys, meetings with specialist consultancies and discussions with experts". Later this work was implemented by Hallegatte et al. (2013), who added their expert estimates of standards of protection for an additional number of coastal cities. Information is thus limited to selected coastal cities, and the original sources are generally not available.

\footnotetext{
${ }^{1}$ http://floods.wri.org
}

This paper aims to present the first version of an opensource, dynamic, community-informed database of FLOod PROtection Standards, FLOPROS. The main motive of FLOPROS is to aid research in flood risk management and in applications such as global hydrological modelling (Bierkens, 2015), and assessments at a smaller scale. The database compiles information from different sources: specialised literature, policy documents and modelling techniques; and aims to incorporate input from the expert community. FLOPROS covers various spatial scales, from the district to the national level. In our search we realised, as Linham et al. (2010) also did, that this information "tends to exist in unpublished reports and with experienced engineers". For this reason, we invite the community of specialists to contribute to improving the coverage, accuracy and resolution of the database. Experts, researchers and operators in specific countries and regions are encouraged to provide pieces of information to FLOPROS, which will ultimately result in a comprehensive body of information available to the flood risk assessment community. Further, because it is apparent that empirical information on protection will remain unavailable for considerable areas of the globe, we propose other ways to fill gaps in the empirical database by means of modelling and inference.

We plan to regularly update FLOPROS to incorporate the contributions of the community. This is necessary for three reasons: (1) to accommodate the flow of new information, (2) because, by its own nature, the implementation of protection is a highly dynamic process, and likely to be accelerated under changing climatic conditions, under demographic and economic pressure, and with increased awareness of and aversion to risk and (3) because flood protection standards are prone to degrade, in the absence of adequate maintenance, and with the effect of climate change on the frequency and magnitude of flood events. Based on the frequency and amount of new entries and updates, progressive versions of the database will be released to include the new information.

\section{Methods}

\subsection{Aggregating multiple layers of information}

FLOPROS is a database of flood protection standards, based on a wide range of sources, and on a modelling approach. The database is structured into three layers of information, namely

a. the design layer, containing information about protection defined by engineers in the design and realisation of currently existing river and coastal flood protection infrastructure;

b. the policy layer, specifying the legislative and normative (or required) standards of protection from river and coastal floods; 


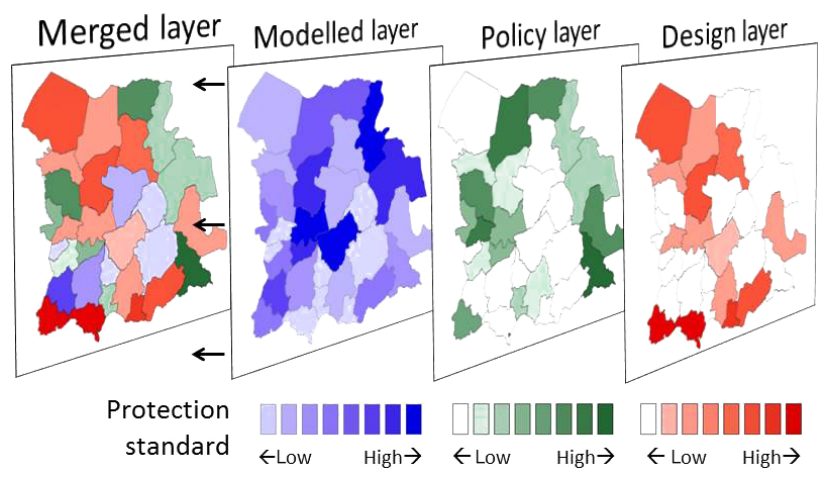

Figure 1. Hierarchical structure of information contained in the FLOPROS database. The design layer provides information on the construction standard of existing protection measures; the policy layer is relative to normative standards of protection; while the model layer calculates protection using flood hazard modelling and a relationship between wealth and flood protection (see Sect. 2.4 for details). These are aggregated into the merged layer, as explained in Sect. 2 .

c. the model layer for river flood protection, which is based on a flood-modelling approach and on the observed relationship between per capita wealth and protection.

While the model layer is based on river flood simulations, the approach can also be expanded to coastal flood risks and coastal protection levels. The general principle at the base of the composition of the FLOPROS database is the incorporation of the best information available for each location. By best information, we mean the most reliable (i.e. trustworthy, accurate or closest to the hypothetical "real" protection standard), the most recent and that with the highest resolution. To this end, a hierarchy is established between the three layers of information, on the basis of how reliable each layer is in representing the actual, existing protection (Fig. 1).

We deem the design layer to be the most reliable to represent existing protection standards because it contains direct information concerning the standards used when designing the protection infrastructure. The two other layers, policy and model, contain information that is a proxy for actual protection. We consider the policy layer to have intermediate reliability because although it provides indication about the intended or required standard of protection, it does not indicate whether such protection is yet realised or enforced. Lastly, the model layer is third in order of reliability because even though partially validated against observations (see Results), it involves a method to indirectly attribute protection information. The individual layers are further explained in Sects. 2.2 to 2.4.

While each of the three layers of information on protection standards can be used separately, depending on the desired scope, for large-scale applications of the database, integration of the three layers of protection standard information is

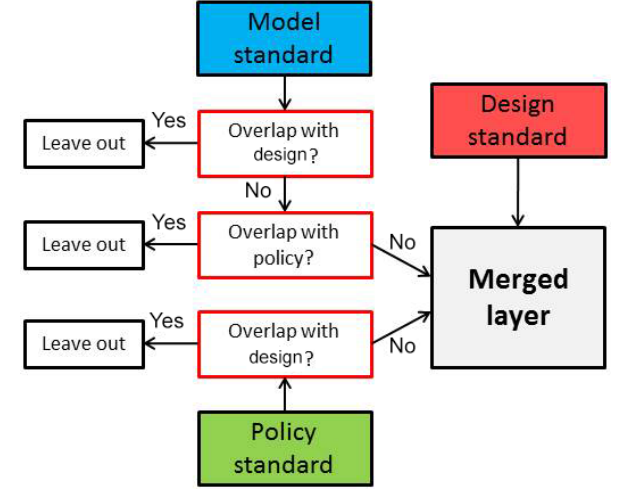

Figure 2. Procedure for the integration of protection standards information from the design, policy and model layers into the merged layer of the FLOPROS database.

desirable. We propose a method for this integration of the three layers into a merged layer, as schematised in Fig. 2. In this method, for places where information is not available in the most reliable layers, information from the subsequent lower layers is employed. In practice, if information is available in the design layer for a given sub-country unit, then this information is included in the merged layer. If no information is contained in the design layer, then the policy layer information is included in the merged layer. Finally, if information is not available even at the policy layer, then the model layer information is included in the merged layer. The rationale for this structure is to enable immediate use of a database that is almost global in extent, while allowing for constant updating of the design layer, as more empirical data on flood protection standards become available.

\subsection{Design layer}

For the design layer, we compiled a list of existing measures against flooding for which a quantification of the protection standard is available in the form of the return period (years) of the flood that the measure is meant to withstand, as per the design of the measure. The sources of information were specialists' and engineering books, peer-reviewed journal articles and scientific studies, technical reports and websites, institutional reports and documents, institutional websites, project websites, corporate websites, newspaper articles, official governmental websites and personal communications with experts (Table 2). For each protection standard included, we assigned a score to the reliability of the source (high, medium, low). This is meant to enable the choice of a best value for locations for which more than one design standard of protection was retrieved, with a significant difference between them. The criteria for assignment of the reliability score were (a) a qualitative estimation of the authoritativeness of the source; (b) the technical completeness of the rel- 
evant information presented and (c) the absence of evident conflicts in the attribution of the protection standard.

\subsection{Policy layer}

For the policy layer, we gathered information on regulated standards of flood protection from policy documents and regulations, and from governmental directives (Table 3). It is often the case that laws and regulations do not correspond to factual, enforced protection, as underlined by Jonkman (2013), given that they are in practice neglected or partially transgressed due to financial and enforcement limitations (de Moel et al., 2009). Nevertheless, this information provides a policy objective towards which action is oriented, thereby assigning a value that is likely more realistic than no protection (Mokrech et al., 2015).

\subsection{Model layer}

For the model layer, we adjusted and extended towards the global scale the approach introduced by Jongman et al. (2014) for deriving protection standards for fluvial flooding in Europe. A modelled protection standard was calculated for administrative units at the first sub-country level ${ }^{2}$ (henceforth simply sub-country unit).

To do this, the following steps were taken.

1. Global maximum and minimum flood protection standards were set. Here, we assumed the minimum protection standard to be no protection. In the GLOFRIS global flood risk model (Ward et al., 2013; Winsemius et al., 2013) schematisation (Ward et al., 2013; see their step 3; no protection means a protection against flood with a return of 2 years (the natural bank-full discharge, following Dunne and Leopold, 1978), and hence this value was used. For the maximum protection standard, we assumed a return period of 1000 years as per Jongman et al. (2014).

2. Next, as it is known that protection standards vary depending on country wealth (Feyen et al., 2012; Jongman et al., 2015), we estimated a maximum and minimum flood protection standard for each income group of the World Bank classification, namely, high-, uppermiddle-, lower-middle-, and low-income group ${ }^{3}$. To do this, firstly, GDP per capita $\left(\mathrm{GDP}_{\mathrm{pc}}\right)$ was calculated per income group in USD 2005 at purchasing power parity. This was done using gridded maps of GDP values and of population density from the IMAGE model, the same maps used in Ward et al. (2013), developed with the method described in van Vuuren et al. (2007). Next, the maximum (minimum) protection standard for a given income group was calculated by dividing its

\footnotetext{
${ }^{2}$ http://www.gadm.org

${ }^{3} \mathrm{http} / / /$ data.worldbank.org/about/country-and-lending-groups
}

$\mathrm{GDP}_{\mathrm{pc}}$ by the GDP $\mathrm{pc}_{\mathrm{pc}}$ of the income group with the highest (lowest) $\mathrm{GDP}_{\mathrm{pc}}$, and multiplying the obtained value by the assumed maximum (minimum) protection standard, i.e. 1000 years (2 years).

3. In the next step, the protection standard for each subcountry unit was estimated. The expected annual damage (EAD) that would occur if no flood protection were in place was calculated using the GLOFRIS model, and then normalised to potential flooded area to yield the EAD per unit of area $\left(E D_{\text {area }}\right)$. For each World Bank income group, the sub-country units with the highest and lowest $\mathrm{EAD}_{\text {area }}$ were assigned the income groupspecific maximum and minimum protection standards (see step 2), respectively, and protection standards for the remaining sub-country units in the income group were linearly interpolated. GLOFRIS only simulates floods on rivers of a Strahler order 6 and higher (Winsemius et al., 2013). Hence, it was not possible to derive a modelled protection standard for catchments with lower Strahler order rivers, corresponding to $\sim 2 \%$ of the Earth's land surface (excluding Antarctica).

Various alternative choices for modelling protection were investigated. Before opting to use the World Bank income groups classification to perform the interpolation (step 2 and 3), we first interpolated uniformly between all subcountry regions across the globe, and also used the United Nations regions classification. Further, we performed interpolation between protection standard values (step 2 and 3), whereby the interpolation was carried out based on both the return period (e.g. 50 years) and the annual exceedance probability (the inverse of the return period; e.g. 0.02). We formulated our decision for the World Bank income groups aggregation, and for using the flood periodicity in the interpolations, on the basis of a comparison of the results with the protection standards included in the design layer (see Sect. 3.3 and Table 4). We visualise the results of these alternative choices for the model layer in Fig. S1 in the Supplement.

We underline that it was not possible to model protection standards in the model layer for coastal floods, due to the lack of essential data sets that resolve the hazard, and therefore the risk in the coastal area. In the absence of spatially resolved risk information, we cannot apply to the coast an approach similar to the one described for the river flood protection standards in the model layer.

\section{Results}

The map in Fig. 3 visualises the merged layer: the aggregation of the protection standards at the scale of the subnational unit, from the three FLOPROS layers. The underlying information, contained in the design, policy, model and merged layer, can be found in the files in the Supplement; the complete lists of protection standards of the design and 


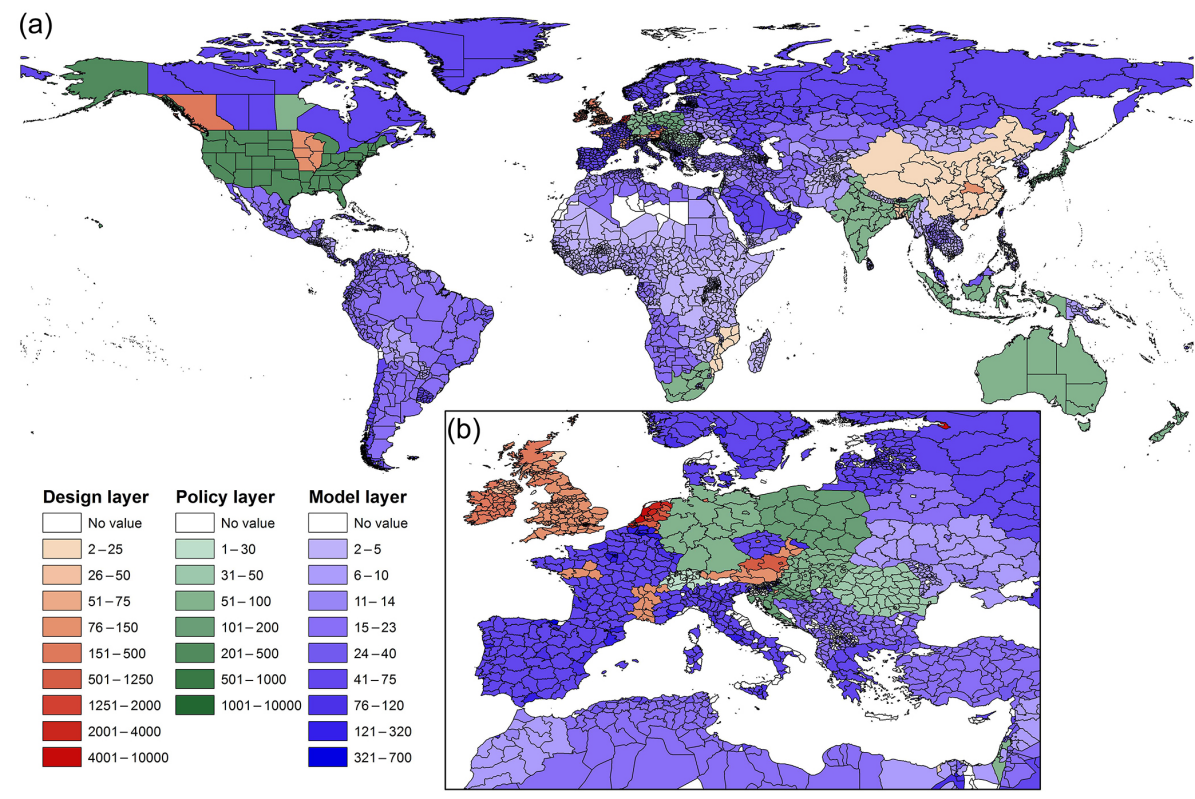

Figure 3. (a) World and (b) Europe maps of flood protection standards contained in the FLOPROS database, for sub-country administrative units (http://www.gadm.org). Standards of the design, policy and model layers (see Sect. 2) are indicated in the red, green and blue colour scales, respectively; these are integrated into the merged layer, which the maps ultimately represent. White indicates no data available (see Sect. 2.4). Note that only the protection standards of the design and policy layers that are coherent with the scale of the sub-country units are included, and therefore part of the information of FLOPROS is not represented in the maps.

policy layers, and their references, are included in an Excel table. Furthermore, a Shapefile provides the information on the protection standards of the model layer along with the information of the design and policy layers that is compatible with the sub-country unit scale of the map, and the resulting merged layer. Information from the design and policy layers that is available at a scale finer than the sub-country unit is not included in the integration process, but remains available for use in its original layer. In this section, we report on the main findings for the design, policy and model layers.

\subsection{Design layer}

Table 1 summarises the different types of information that are gathered and organised within the design layer. A total of 181 entries have been included in this layer. For each entry it is specified whether the measure is meant to counter riverine flood, coastal flood or both. Empirical information on protection standards seems to be more available for river floods (102 out of 181 entries). The spatial resolution is heterogeneous, ranging from city-scale (the most common with 107 out of 181 entries) to country-scale. Most of the information is gathered from institutional and technical reports.

On many occasions, information is retrieved in the form of a range of protection standard values, with a maximum and minimum value, normally to account for the spatial heterogeneity of the location, and/or for the necessarily vast uncer-

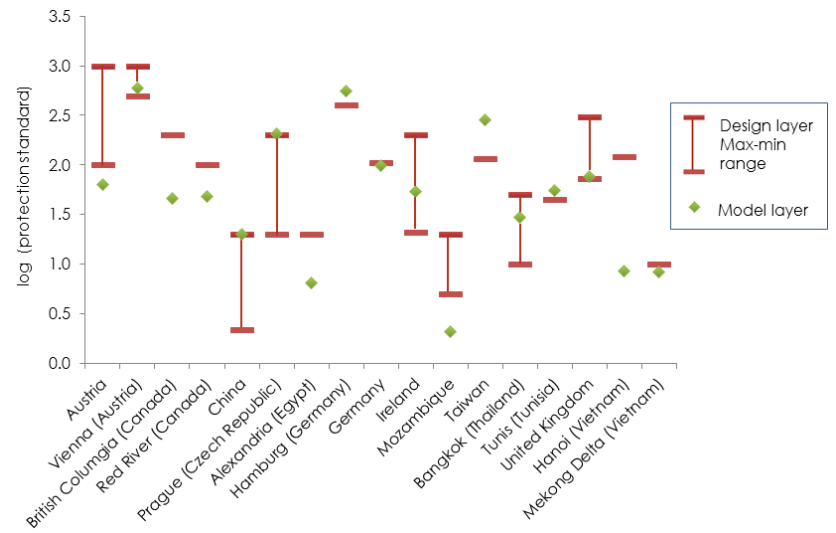

Figure 4. Comparison of the protection standards included in the model layer (green diamonds) to those in the design layer (red bars), for locations where the two layers can be compared on the same scale. For the design layer, a range of values, when available, or a single value are plotted. To enhance the visualisation, values are reported as a logarithm of the protection standard, expressed as the return period.

tainties associated with the estimation of the magnitude and the probability of flood events (see also Fig. 4).

Although in many sources the type of flood defences are not explicitly specified, it appears that measures are mostly structural, namely dikes and levees, such as the Thames Barrier for London (Risk \& Policy Analysts Limited, 2006), and 
Table 1. Overview of the characteristics of information contained in the design layer of the FLOPROS database (the full database is available in the Supplement).

\begin{tabular}{llrr}
\hline Characteristic & Subdivision & No. entries & $\%$ \\
\hline \multirow{4}{*}{ Type of flood hazard } & River floods & 102 & 56 \\
& Coastal floods & 32 & 18 \\
& Both & 35 & 19 \\
& Unspecified & 12 & 7 \\
\hline \multirow{5}{*}{ Scale } & City & 107 & 59 \\
& River stretch & 37 & 20 \\
& Region & 23 & 13 \\
& Country & 14 & 8 \\
\hline \multirow{5}{*}{ Reference type } & Technical report & 52 & 29 \\
& Institutional report/document & 47 & 26 \\
& Institutional website & 15 & 8 \\
& Personal communication & 12 & 7 \\
& Journal article & 11 & 6 \\
& Engineering book & 9 & 5 \\
& Specialists book & 7 & 4 \\
& Technical website & 6 & 3 \\
& Newspaper article & 6 & 3 \\
& Scientific study & 6 & 3 \\
& Project website & 3 & 2 \\
& Corporate website & 3 & 2 \\
& Wikipedia (not further specified) & 2 & 1 \\
& Not available & 2 & 1 \\
\hline \multirow{5}{*}{ Reliability } & High & 99 & 57 \\
& Medium & 54 & 31 \\
& Low & 21 & 12 \\
\hline
\end{tabular}

retention areas. "Soft" and "green" measures for flood protection (Cheong et al., 2013; Hinkel and Bisaro, 2015) tend not to have a standard of protection specified in terms of return period years, although exceptions exist, such as the flood control area realised for the town of Kruibeke, Belgium, combining flood protection with habitat creation, for which a protection standard of 350 years is specified (EU OURCOAST Project, 2014).

\subsection{Policy layer}

The policy layer is composed of 71 entries, considerably less than for the design layer. Table 2 summarises the characteristics of the information gathered in this layer. A list of the countries for which policy standards of flood protection have been retrieved, either at country, regional, or city scale, is provided in Table 3. In contrast with the design layer, river and coastal flood protection entries are more balanced, and information is much more available at the country scale, than at the city scale. The main sources are again technical and institutional reports, followed by specialists' books.

Mostly, policy protection standards are provided in the form of coding of areas, which is assigning different standards of protection to an area based on the type of use (e.g. residential, industrial, agricultural). This is for example the case in the UK, where policy standards seem to range from 1 to 300 years, depending on the land use (DEFRA,
Table 2. Overview of the characteristics of information contained in the policy layer of the FLOPROS database (the full database is available in the Supplement).

\begin{tabular}{llrr}
\hline Characteristic & Subdivision & No. entries & $\%$ \\
\hline \multirow{5}{*}{ Type of flood hazard } & River floods & 29 & 40 \\
& Coastal floods & 11 & 11 \\
& Both & 28 & 39 \\
& Unspecified & 4 & 6 \\
\hline \multirow{5}{*}{ Scale } & City & 9 & 13 \\
& River stretch & 2 & 3 \\
& Region & 8 & 11 \\
& Country & 50 & 70 \\
& Continent & 2 & 3 \\
\hline \multirow{5}{*}{ Reference type } & Technical report & 22 & 31 \\
& Institutional report/document & 19 & 27 \\
& Institutional website & 5 & 7 \\
& Personal communication & 3 & 4 \\
& Journal article & 8 & 11 \\
& Specialists book & 6 & 8 \\
& Technical website & 2 & 3 \\
& Scientific study & 1 & 1 \\
& Project website & 3 & 4 \\
& Not available & 2 & 3 \\
\hline
\end{tabular}

Table 3. Countries for which indications of the presence of policy/legal standards of protection at national, regional or city scale were found.

\begin{tabular}{lccc}
\hline Countries & $\begin{array}{c}\text { National- } \\
\text { scale }\end{array}$ & $\begin{array}{c}\text { Regional- } \\
\text { scale }\end{array}$ & $\begin{array}{c}\text { City- } \\
\text { scale }\end{array}$ \\
\hline Australia & & & $\mathrm{X}$ \\
Belgium & $\mathrm{X}$ & $\mathrm{X}$ & \\
Canada & $\mathrm{X}$ & & $\mathrm{X}$ \\
China & $\mathrm{X}$ & & $\mathrm{X}$ \\
Denmark & $\mathrm{X}$ & & \\
Finland & $\mathrm{X}$ & $\mathrm{X}$ & $\mathrm{X}$ \\
Germany & $\mathrm{X}$ & & \\
India & $\mathrm{X}$ & & \\
Ireland & $\mathrm{X}$ & & \\
Japan & $\mathrm{X}$ & $\mathrm{X}$ & \\
the Netherlands & $\mathrm{X}$ & & \\
Poland & $\mathrm{X}$ & & \\
Switzerland & $\mathrm{X}$ & $\mathrm{X}$ & $\mathrm{X}$ \\
UK & $\mathrm{X}$ & & $\mathrm{X}$ \\
USA & & & \\
\hline
\end{tabular}

1999). A recurrent form of regulating flood risk is the limitation of new developments in areas subject to flooding of a certain return period, which often depends on the urban, residential, rural or industrial use of the land.

\subsection{Model layer}

By default, the model layer gives values for the majority of the subnational units (Fig. 3). To test its validity, we compared it to the design layer values, which are deemed clos- 
Table 4. Summary of the sensitivity analysis for the model layer, and comparison to the design layer. The criteria for the comparison are the number of occurrences in which the model layer value falls within the range of design layer values, and the average offset between the model layer and the design layer values.

\begin{tabular}{|c|c|c|c|}
\hline $\begin{array}{l}\text { Method of aggregation } \\
\text { of sub-country units }\end{array}$ & Calculation using & $\begin{array}{l}\text { Value falls } \\
\text { within the } \\
\text { design layer } \\
\text { range }^{1} \text { (no. of } \\
\text { occurrences) }^{\text {occula }}\end{array}$ & $\begin{array}{l}\text { Average offset } \\
\text { from the } \\
\text { design layer }{ }^{2} \\
\text { (exceedance } \\
\text { probability) }\end{array}$ \\
\hline World Bank income groups & $\begin{array}{l}\text { return period } \\
\text { exceedance probability }\end{array}$ & $\begin{array}{l}5 \text { out of } 8 \\
4 \text { out of } 8\end{array}$ & $\begin{array}{l}0.053 \\
0.059\end{array}$ \\
\hline United Nations regions & $\begin{array}{l}\text { return period } \\
\text { exceedance probability }\end{array}$ & $\begin{array}{l}3 \text { out of } 8 \\
2 \text { out of } 8\end{array}$ & $\begin{array}{l}0.064 \\
0.088\end{array}$ \\
\hline No aggregation & $\begin{array}{l}\text { return period } \\
\text { exceedance probability }\end{array}$ & $\begin{array}{l}4 \text { out of } 8 \\
0 \text { out of } 8\end{array}$ & $\begin{array}{l}0.166 \\
0.401\end{array}$ \\
\hline
\end{tabular}

${ }^{1}$ For the eight comparisons for which a range of design layer values is available (see Fig. 4). ${ }^{2}$ We calculate the average of the absolute value of each offset between the model layer and the design layer (i.e. the mean between the max and min value, if a range is available) protection standard, expressed in terms of exceedance probability.

est to reality (Fig. 4). Moreover, as mentioned in Sect. 2.4, a range of options have been tested using different aggregations of sub-country units for interpolation, and different units for protection standards in the interpolations. Therefore, the comparison with the design layer serves also as a basis for the choice of the most appropriate method for the model layer of FLOPROS.

We use two criteria for the selection of the most appropriate solution by comparison with the design layer: (1) the number of occurrences in which the model layer value falls within the range of design layer values; and (2) the average offset between the model layer and the design layer values.

Table 4 shows the degree of matching between the output of the selected solution for the model layer and the design layers, for a number of spatially coherent comparisons (where the scale of information in the design layer matches the resolution of the model layer). The solution of aggregating by World Bank income groups and to use return period years for the interpolations yielded a better performance according to both criteria, with its values either falling within the range provided by the design layer or close to the only available design layer value most of the time (Fig. 4). We therefore considered it the one most in agreement with the design layer and decided to adopt it for inclusion in FLOPROS. The comparison of all solutions for the model layer to the design layer values is found in Fig. S1.

The highest standards of protection in the model layer are found in North America, from about a 380-year return period in the west coast of the United States, to about 20 years in Mexico; in Europe, from about a 250-year return period in regions of west Germany to about a 20 -year return period in eastern European countries, with peaks of more than 500year return periods in specific cities like Vienna, Paris and
London; and in Russia, Australia, Saudi Arabia and Oman, with values around 50 .

South America is protected with standards ranging from about a 45-year return period in Uruguay and Chile, to 6 in Bolivia, Paraguay, Guyana and French Guiana. Africa presents protection ranging from 16 in northern and in southern African countries, to values of 2 in Saharan, sub-Saharan, tropical and western Africa, with peaks of about 115 in Egypt and 45 in Equatorial Guinea. Protection in Asia ranges from peaks of about 150 in Japan, to values around 2 in countries like Myanmar, Cambodia, Afghanistan or Nepal.

\section{Discussion and future developments of FLOPROS}

In the FLOPROS database, we have compiled information on standards of flood protection from a variety of available sources in the literature (design and policy layers), and with an approach based on modelling (model layer). The collected information ranges widely in spatial scale and the reliability of the source. The differences in spatial scale pose a substantial challenge to the comparison, integration and visual representation (Fig. 3) of the information from the three layers (see Sect. 3.3). In fact, while the model layer is based on the sub-country units, information in the design and policy layers is gathered at different spatial resolutions. Therefore, while the composite, three-layer integration of the database that we propose (Sect. 2.5) is carried out at the scale of the sub-country units that are used in the model layer, a substantial part of the design and policy layers' information that is available at finer scales is excluded, but remains available in the respective layers. On the other hand, the observed range in the reliability of the sources implies that not all information included can be equally trusted. Although uniform reli- 
ability cannot realistically be achieved, this limitation can be addressed by the strategies that we propose in Sect. 4.1.

\subsection{Type of protection}

The design and policy layers of FLOPROS comprise, at present, almost exclusively information on structural measures of flood protection. These are construction works, commonly dikes, levees and reservoirs, but also less common solutions, such as river bypass channels (realised for example for the Donau in Vienna; Zurich, 2014), and are often referred to as "grey"; but examples of "soft" measures like management plans (as in the case of Copenhagen; City of Copenhagen, 2012) are included as well. Also, entries in the database commonly refer to hazard-reducing measures, i.e. measures aimed at addressing the frequency and the magnitude of flood events. In recent years, flood risk-reduction practices have increasingly been considered that rather than addressing flood hazard, aim to reduce the exposure or the vulnerability to floods (e.g. Nicholls et al., 2008; Bouwer et al., 2009; Bubeck et al., 2011). For example, relocation of people and assets outside of floodplains of a given return period is a measure that addresses exposure; and dry-proofing (sealing off to water) residential buildings is a measure to reduce vulnerability of the assets in a flood-prone area. Further, since the introduction of the concept of Integrated Flood Risk Management, a new paradigm, has taken foot, entailing hybrid and mixed approaches (e.g. Sayers et al., 2013) that combine approaches to simultaneously reduce the hazard, exposure and vulnerability elements of risk (as defined in Kron, 2005; Aerts et al., 2014). All the above approaches and measures aim to reduce risk, and are therefore important for the risk calculation, that FLOPROS has the ambition to improve. We therefore suggest that future, expanded versions of the FLOPROS database should also present approaches to include exposure- and vulnerability-reducing measures.

\subsection{Comparing the FLOPROS layers}

To investigate the coherence of the database in its three layers, we compared the values of protection standards included in the design layer and in the two "proxy" layers, the model and the policy layers. For the sub-country units for which FLOPROS has a protection value for both the design and the model layers, we found highly significant correlation between the two data sets, with both parametric and nonparametric tests (Pearson's $r=0.76$; Spearman's $\rho=0.70$; $p \ll 0.001$ for both correlation coefficients) (Fig. 5a). Due to the strong positive skewness of the data sets in both the design and model layers, data were log-transformed prior to assessing the correlation with the Pearson's $r$ coefficient.

The correlation between the log-transformed data sets of the design and policy layers is also positive, but due to the low number of observations $(n=13)$ it does not reach statistical significance (Pearson's $r=0.46$ and $p=0.12$; Spear-
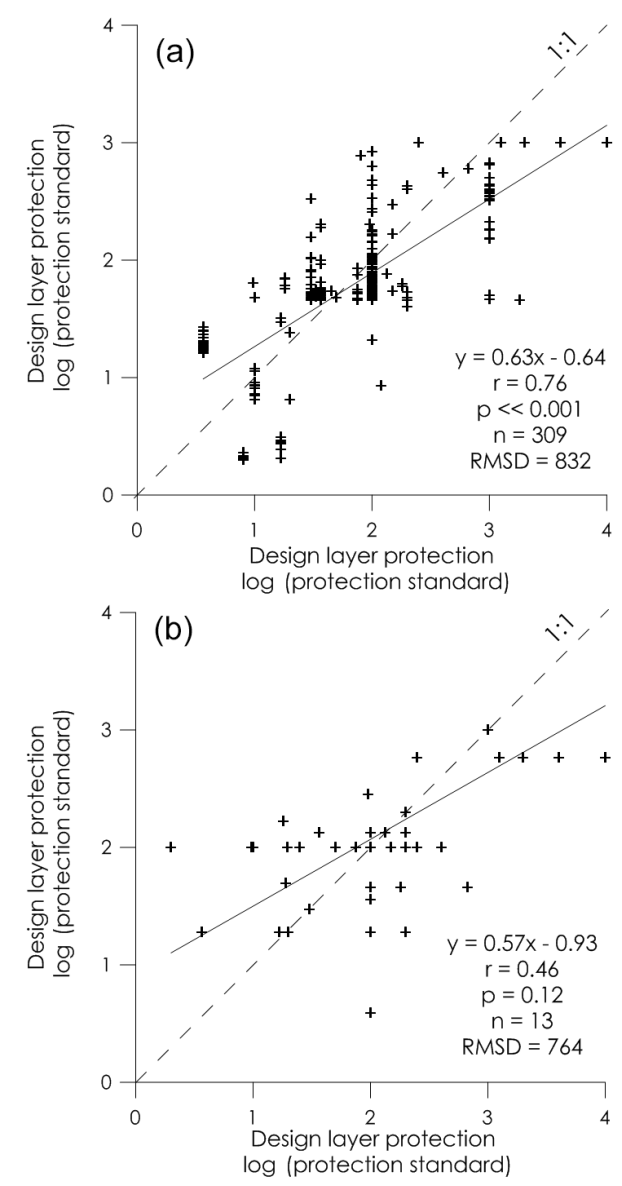

Figure 5. Correlation between data sets of (a) the design and of the model layers, and (b) the design and the policy layers. A logtransformation was applied to the protection standard values expressed as return periods. The slope and intercept of the regression curves are shown, along with the $r$ Pearson's correlation coefficient (with the $p$ value of the correlation) and the root-mean-square deviation (RMSD). When a minimum and maximum protection value were present, the average of the annual exceedance probabilities (the inverse of the return period) was taken.

man's $\rho=0.41$ and $p=0.17$ ) (Fig. 5b), This implies that, for the sub-country units for which both design and policy information was retrieved, enforced protection reflects, to some extent, the policy objectives. On the other hand, the root-mean-square deviation of the policy values (from the design layer ones) is lower than that of the model layer values: 764 instead of 832 (or 0.376 instead of 0.503 , for the logtransformed data). This means that overall, the policy layer values are closer to the design layer ones.

We conclude that both the model and the policy layers can be considered useful proxies for actual, enforced protection as included in our design layer, with the model layer showing a more solid correlation, and the policy layer a smaller deviation from the design values. 
With regards to the hierarchy of the three layers of information, we need to stress that the chosen order (see Sect. 2.5), with the design layer on the top, the policy layer underneath and the model layer at the bottom, should not be interpreted as a rigid prescription. In fact, because the model layer approximates the design layer values closer than the policy layer, it could be argued that the model layer should feature after the design layer in the hierarchy. However, because many factors could be considered to argue for the one or the other hierarchical solution, we emphasise that layers in FLOPROS should be kept separated, and propose that users could make their own decisions regarding how to integrate them to better fit their purposes.

Because the main motivation of FLOPROS is to provide a practical tool to support research in flood risk management, we focus on its potential applications, such as global hydrological modelling (Bierkens, 2015), and also other domains as land use planning (e.g. Aerts et al., 2005). The layers in the database can be utilised independently from each other, based on the scope of the investigation. The hierarchical overlaying of the three layers permits the issue of aggregation of heterogeneous information from the layers to be overcome. Therefore, information can be retrieved and used both in the form of single items, represented by single entries of the database, and of aggregated information, from more entries and/or from more layers. This possibility especially reflects the necessities of large-scale assessments of flood risk (e.g. Ward et al., 2013). Further, since information of the design and policy layers is presented in the form of maximum and minimum values, the investigator can choose to run the modelling exercise, either under the assumption of high or of low standards of protection.

A number of limitations, however, still persist; in the following we discuss them and propose directions to overcome them.

\subsection{Outlook to future versions of FLOPROS}

As visible in the mapped visualisation of FLOPROS (Fig. 3) on global and European scale, vast and densely populated areas in developing regions such as Africa, South America and the Middle East clearly have less empirical information compared to developed countries. We advance a number of strategies aimed to extend the coverage, resolution and reliability of future versions of FLOPROS.

\subsubsection{Towards an online platform for FLOPROS}

The FLOPROS database could greatly benefit from the support of an online platform. This would serve two functions: (1) to enable and manage the entry of new information by experts; and (2) for users to visualise and download FLOPROS.

Regarding point 1 , experts, operators and researchers with a project portfolio in the regions of the database where data coverage is scarcer (Fig. 3) are in the position of providing local insights about protection standards, to help fill the vast gaps still present in FLOPROS.

Regarding point 2 , we propose that the database should be open and freely accessible to every potential user on the internet. This will also ensure that users in less developed countries, and researchers with limited financial means will be able to use information from FLOPROS for hazard and risk assessment in their region of focus.

To allow efficient access to the database, both to the contributing community and to end users, it is necessary to find a suitable format for its publication. In this regard, a tool should be identified that presents at least three main characteristics. (1) It should be free and open-source, and therefore readily available to any user worldwide; (2) it should provide the possibility for straightforward and structured update of information from the community, for example by including a form that can be filled in online, such as proposed in Table S2 in the Supplement for this manuscript; (3) it should permit quality control of information by the custodians of the database; and (4) it should permit information at different spatial scales: river basin and sub-basin, administrative and also hybrid units.

Further, another interesting potential of an online platform for FLOPROS is the potential to enable crowdsourcing of information about actual dikes and levees, for example using volunteered geographical information data sets (e.g. Haklay and Weber, 2008; Haklay et al., 2014). This could provide the necessary parameters to convert the presence of dams and reservoirs from the GRanD database (Lehner et al., 2011) into protection standards, as described below.

\subsubsection{Protection from dams and reservoirs}

A database of existing dams and reservoirs with a global coverage currently exists, the GRanD database ${ }^{4}$ (Lehner et al., 2011). The database is nearly exhaustive and comprises 6862 dams and 6824 associated reservoirs. We envision the following strategy to extract flood protection information from GRanD.

For each dam and reservoir in GRanD, it is specified whether flood control is its main or its secondary use. A conservative estimate of the amount of flood storage, available through dam operation, can therefore be made, assuming that a portion of the flood control reservoirs is available for this purpose. Consequently, a conservative estimate of their effect on flood hazard levels, and thus the standard of flood protection they offer, can be assigned to the associated river stretches and to the main cities downstream in the proximity (flood protection typically reduces further downstream of the dam, as more tributaries enter the river). Expert judgment could be employed to determine the general standards of flood protection associated with dams and reservoirs, and the extent of the protected area downstream. Alternatively,

\footnotetext{
${ }^{4}$ http://www.gwsp.org/products/grand-database.html
} 
basin-specific hydrological modelling (e.g. Aerts et al., 1999) with and without consideration of this available flood storage could yield more accurate estimations of protection.

\subsubsection{Using statistical correlations}

While we envision that with the community's collaboration, a better spatial coverage of the design and policy layers can be achieved in the future, we nevertheless expect that for many areas, empirical and normative information might neither be retrieved, nor exist. A strategy to achieve global coverage and fill the persistent gaps, alternative to the approach devised for the model layer, is to compute correlations between standards of protection in FLOPROS (using information from the design and policy layers), and socioeconomic indices, at various scales. If a suitable multiple regression model is found, it could then be applied to infer index-derived protection standards for those missing regions.

This is not a trivial exercise, and a relationship between wealth of cities and protection standards has been postulated before (e.g. Nicholls et al., 2008). Linham et al. (2010) explored the correlations between their 36 coastal cities protection data set versus country GDP/capita and exposed population, with poor results. They did show that the "demand for safety" metric of the DIVA impact model could predict the protection standard within a factor of 10. Later, Feyen et al. (2012) used GDP to infer protection standards on an EU scale. Jongman et al. (2015) provided global empirical evidence on a general relationship between GDP and vulnerability, but did not relate this specifically to protection standards. An in-depth investigation of some African countries, used as case studies, suggested political and economic conditions that foster action towards disaster risk management (CCAPS, 2014). Our new database enables an extensive exploration of the socioeconomic determinants of flood protection (Cutter and Finch, 2008). Our preliminary results indicate that at the country scale, significant correlations appear to exist between the protection standard in the design and policy layers and certain economic and governance indicators. For instance, the "government spending" index accounts for the total expenditure of governments as a proportion of the country's GDP, while the "freedom from corruption" index reflects experts' opinion on local perception of corruption in most countries (using Transparency International's Corruption Perceptions Index) (The Heritage Foundation, 2014 and references therein) (Fig. 6). The significant correlations suggest that countries with higher public spending, and countries where corruption is less widespread, tend to have higher flood protection standards, as included in the country-scale entries of our design and policy layers. Future research could focus on further examining such relationships in greater detail.

\footnotetext{
${ }^{5}$ http://www.heritage.org/index/book/methodology
}
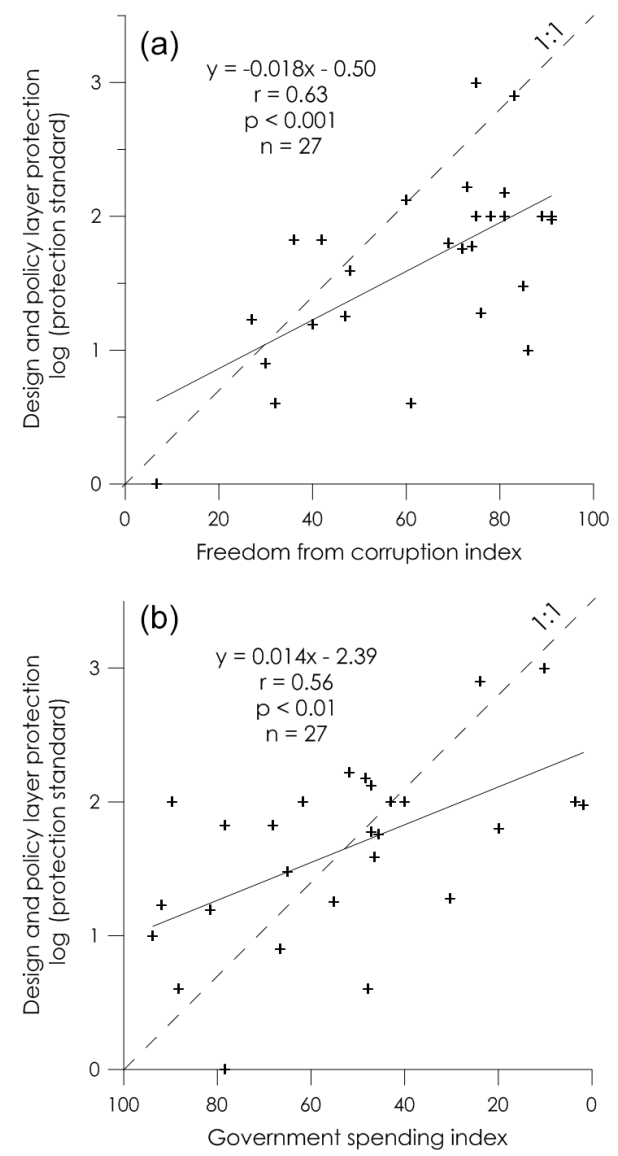

Figure 6. Examples of correlation of flood protection standards, as from our design and policy layer, with economic and policy indexes: (a) with the "government spending" index (note that the axis is reversed, because a 100 value of the index indicates minimum government spending, and conversely), and (b) with the "freedom from corruption" index (The Heritage Foundation, 2014 (http://www.heritage.org/index/book/methodology); and references therein). For clarity, more freedom from corruption and more government spending correspond to higher flood protection standards.

\section{Conclusions}

We launch the first version of the global database of FLOod PROtection Standards, FLOPROS. The database aims to gather up-to-date, reliable and high-resolution information available on protection standards, and to maintain a database that can be of use to research and management of flood risk, from the local to the global scale. We structured FLOPROS in multiple layers of flood protection standards: a design layer, composed by information about standards of actual existing protection; a policy layer, reflecting normative objectives for protection standards; and a model layer, based on a modelling approach, which we validated against the design layer observations. We suggest that protection standards provided in the policy and in the model layer are valid proxies for actual protection standards. 
We concomitantly launch a call to the expert community to contribute new and missing information to further versions of FLOPROS. We propose that the set-up of an online platform to enter and organise information in the database could facilitate this process. Further, we propose strategies that could enhance the completeness, reliability and resolution of the database.

\section{The Supplement related to this article is available online at doi:10.5194/nhess-16-1049-2016-supplement.}

Author contributions. Paolo Scussolini, Jeroen C. J. H. Aerts, Philip J. Ward, Laurens M. Bouwer, Hessel C. Winsemius and Brenden Jongman designed the study. Paolo Scussolini collected information in the design layer of the database. Philip J. Ward and Brenden Jongman created the model layer of the database. Paolo Scussolini, Jeroen C. J. H. Aerts and Philip J. Ward prepared the manuscript with contributions from all co-authors.

Acknowledgements. This research was funded as part of the Aqueduct Global Flood Analyzer project, via subsidy 5000002722 from the Netherlands Ministry of Infrastructure and the Environment. The project is convened by the World Resources Institute. Philip J. Ward received additional funding from the Netherlands Organisation for Scientific Research (NWO) in the form of a VENI grant (grant no. 863-11-011). Jeroen C. J. H. Aerts acknowledges support of NWO VICI grant 453-14-006. The work has further benefitted from support of the ECONADAPT and RISES-AM- projects, under EU FP7: grant agreement no. 603906 (ECONADAPT), and no. 603396 (RISES-AM-). We are grateful to Corine Ten Velden, Dennis Wagenaar, Qian Ke and many colleagues at the Institute of Environmental Studies (Vrije Universiteit Amsterdam) and at Deltares for contributing information to the database.

Edited by: T. Glade

Reviewed by: L. Alfieri and one anonymous referee

\section{References}

Aerts, J. C. J. H., Kriek, M., and Schepel, M.: STREAM (Spatial tools for river basins and environment and analysis of management options): 'set up and requirements', Phys. Chem. Earth B, 24, 591-595, doi:10.1016/S1464-1909(99)00049-0, 1999.

Aerts, J. C. J. H., Van Herwijnen, M., Janssen, R., and Stewart, T.: Evaluating Spatial Design Techniques for Solving Landuse Allocation Problems, J. Environ. Pl. Manage., 48, 121-142, doi:10.1080/0964056042000308184, 2005.

Aerts, J. C. J. H., Botzen, W. J. W., Emanuel, K., Lin, N., de Moel, H., and Michel-Kerjan, E. O.: Evaluating Flood Resilience Strategies for Coastal Megacities, Science, 344, 473475, doi:10.1126/science.1248222, 2014.
Alfieri, L., Feyen, L., Dottori, F., and Bianchi, A.: Ensemble flood risk assessment in Europe under high end climate scenarios, Global Environ. Change, 35, 199-212, doi:10.1016/j.gloenvcha.2015.09.004, 2015.

Arnell, N. W. and Gosling, S. N.: The impacts of climate change on river flood risk at the global scale, Climatic Change, 134, 387 401, doi:10.1007/s10584-014-1084-5, 2014.

Bierkens, M. F. P.: Global hydrology 2015: State, trends, and directions, Water Resour. Res., 51, 4923-4947, doi:10.1002/2015WR017173, 2015.

Bouwer, L. M., Bubeck, P., Wagtendonk, A. J., and Aerts, J. C. J. H.: Inundation scenarios for flood damage evaluation in polder areas, Nat. Hazards Earth Syst. Sci., 9, 1995-2007, doi:10.5194/nhess9-1995-2009, 2009

Bubeck, P., de Moel, H., Bouwer, L. M., and Aerts, J. C. J. H.: How reliable are projections of future flood damage?, Nat. Hazards Earth Syst. Sci., 11, 3293-3306, doi:10.5194/nhess-11-32932011, 2011.

CCAPS: Institutional capacity for natural disasters: case studies in Africa, in: Climate Change and African Political Stability, edited by: Bussell, J., Robert S. Strauss Center for International Security and Law, Austin, Texas, 216 pp., 2014.

Cheong, S.-M., Silliman, B., Wong, P. P., van Wesenbeeck, B., Kim, C.-K., and Guannel, G.: Coastal adaptation with ecological engineering, Nat. Clim. Change, 3, 787-791, doi:10.1038/nclimate1854, 2013.

City of Copenhagen: Cloudburst Management Plan, http://kk.sites. itera.dk/apps/kk_pub2/pdf/1019_811SkHGSvS.pdf (last access: November 2014), 2012.

Cutter, S. L. and Finch, C.: Temporal and spatial changes in social vulnerability to natural hazards, P. Natl. Acad. Sci. USA, 105, 2301-2306, doi:10.1073/pnas.0710375105, 2008.

Dankers, R., Arnell, N. W., Clark, D. B., Falloon, P. D., Fekete, B. M., Gosling, S. N., Heinke, J., Kim, H., Masaki, Y., Satoh, Y., Stacke, T., Wada, Y., and Wisser, D.: First look at changes in flood hazard in the Inter-Sectoral Impact Model Intercomparison Project ensemble, P. Natl. Acad. Sci. USA, 111, 3257-3261, doi:10.1073/pnas.1302078110, 2014.

DEFRA: Flood and Coastal Defence Project Appraisal Guidance Economic Appraisal, FCDPAG3, Department for Environment, Food and Rural Affairs, 102 pp., 1999.

de Moel, H., van Alphen, J., and Aerts, J. C. J. H.: Flood maps in Europe - methods, availability and use, Nat. Hazards Earth Syst. Sci., 9, 289-301, doi:10.5194/nhess-9-289-2009, 2009.

de Moel, H., Jongman, B., Kreibich, H., Merz, B., PenningRowsell, E., and Ward, P. J.: Flood risk assessments at different spatial scales, Mitig. Adapt. Strateg. Glob. Change, 20, 865-890, doi:10.1007/s11027-015-9654-z, 2015.

Dunne, T. and Leopold, L.: Water in environmental planning, W. H. Freeman \& Co., San Francisco, 818 pp., 1978.

EU OURCOAST Project: http://ec.europa.eu/ourcoast/print.cfm? articleID=9, last access: November 2014.

Feyen, L., Dankers, R., Bódis, K., Salamon, P., and Barredo, J.: Fluvial flood risk in Europe in present and future climates, Climatic Change, 112, 47-62, doi:10.1007/s10584-011-0339-7, 2012.

Haklay, M. and Weber, P.: OpenStreetMap: UserGenerated Street Maps, IEEE Pervas. Comput., 7, 12-18, doi:10.1109/mprv.2008.80, 2008. 
Haklay, M., Antoniou, V., Basiouka, S., Soden, R., and Mooney, P.: Crowdsourced geographic information use in government, Report to World Bank GFDRR, London, UK, 76 pp., 2014.

Hall, J. W.: Editorial: steps towards global flood risk modelling, J. Flood Risk Manage., 7, 193-194, doi:10.1111/jfr3.12119, 2014.

Hall, J. W., Brown, S., Nicholls, R. J., Pidgeon, N. F., and Watson, R. T.: Proportionate adaptation, Nat. Clim. Change, 2, 833-834, 2012.

Hallegatte, S., Green, C., Nicholls, R. J., and Corfee-Morlot, J.: Future flood losses in major coastal cities, Nat. Clim. Change, 3, 802-806, doi:10.1038/nclimate1979, 2013.

Hanson, S., Nicholls, R., Ranger, N., Hallegatte, S., Corfee-Morlot, J., Herweijer, C., and Chateau, J.: A global ranking of port cities with high exposure to climate extremes, Climatic Change, 104, 89-111, doi:10.1007/s10584-010-9977-4, 2011.

Hinkel, J. and Bisaro, A.: A review and classification of analytical methods for climate change adaptation, Wiley Interdisciplinary Reviews: Climate Change, 6, 171-188, doi:10.1002/wcc.322, 2015.

Hinkel, J., van Vuuren, D., Nicholls, R., and Klein, R. T.: The effects of adaptation and mitigation on coastal flood impacts during the 21st century. An application of the DIVA and IMAGE models, Climatic Change, 117, 783-794, doi:10.1007/s10584-012-05648, 2013.

Hinkel, J., Lincke, D., Vafeidis, A. T., Perrette, M., Nicholls, R. J., Tol, R. S. J., Marzeion, B., Fettweis, X., Ionescu, C., and Levermann, A.: Coastal flood damage and adaptation costs under 21st century sea-level rise, P. Natl. Acad. Sci. USA, 111, 3292-3297, doi:10.1073/pnas.1222469111, 2014.

Hirabayashi, Y., Mahendran, R., Koirala, S., Konoshima, L., Yamazaki, D., Watanabe, S., Kim, H., and Kanae, S.: Global flood risk under climate change, Nature Clim. Change, 3, 816-821, doi:10.1038/nclimate1911, 2013.

IPCC: Climate Change 2014: Impacts, Adaptation, and Vulnerability. Part A: Global and Sectoral Aspects, in: Contribution of Working Group II to the Fifth Assessment Report of the Intergovernmental Panel on Climate Change, edited by: Field, C. B., Barros, V. R., Dokken, D. J., Mach, K. J., Mastrandrea, M. D., Bilir, T. E., Chatterjee, M., Ebi, K. L., Estrada, Y. O., Genova, R. C., Girma, B., Kissel, E. S., Levy, A. N., MacCracken, S., Mastrandrea, P. R., and White, L. L., Cambridge University Press, Cambridge, UK and New York, NY, USA, 1132 pp., 2014.

Jongman, B., Ward, P. J., and Aerts, J. C. J. H.: Global exposure to river and coastal flooding: Long term trends and changes, Global Environ. Change, 22, 823-835, doi:10.1016/j.gloenvcha.2012.07.004, 2012.

Jongman, B., Hochrainer-Stigler, S., Feyen, L., Aerts, J. C. J. H., Mechler, R., Botzen, W. J. W., Bouwer, L. M., Pflug, G., Rojas, R., and Ward, P. J.: Increasing stress on disaster-risk finance due to large floods, Nat. Clim. Change, 4, 264-268, doi:10.1038/nclimate2124, 2014.

Jongman, B., Winsemius, H. C., Aerts, J. C. J. H., Coughlan de Perez, E., van Aalst, M. K., Kron, W., and Ward, P. J.: Declining vulnerability to river floods and the global benefits of adaptation, P. Natl. Acad. Sci. USA, 112, E2271-E2280, doi:10.1073/pnas.1414439112, 2015.

Jonkman, S. N.: Advanced flood risk analysis required, Nat. Clim. Change, 3, 1004-1004, doi:10.1038/nclimate2031, 2013.
Kron, W.: Flood Risk = Hazard · Values · Vulnerability, Water Int., 30, 58-68, doi:10.1080/02508060508691837, 2005.

Kundzewicz, Z. W., Kanae, S., Seneviratne, S. I., Handmer, J., Nicholls, N., Peduzzi, P., Mechler, R., Bouwer, L. M., Arnell, N., Mach, K., Muir-Wood, R., Brakenridge, G. R., Kron, W., Benito, G., Honda, Y., Takahashi, K., and Sherstyukov, B.: Flood risk and climate change: global and regional perspectives, Hydrolog. Sci. J., 59, 1-28, doi:10.1080/02626667.2013.857411, 2013.

Lehner, B., Liermann, C. R., Revenga, C., Vörösmarty, C., Fekete, B., Crouzet, P., Döll, P., Endejan, M., Frenken, K., Magome, J., Nilsson, C., Robertson, J. C., Rödel, R., Sindorf, N., and Wisser, D.: High-resolution mapping of the world's reservoirs and dams for sustainable river-flow management, Front. Ecol. Environ., 9, 494-502, doi:10.1890/100125, 2011.

Linham, M., Green, C., and Nicholls, R.: Costs of adaptation to the effects of climate change in the world's large port cities, Work stream 2, Report 14 of the AVOID programme, $238 \mathrm{pp}$., http://www.metoffice.gov.uk/media/pdf/k/s/ AVOID_WS2_D1_14_20100701.pdf (last access: April 2016), 2010.

Merz, B., Aerts, J., Arnbjerg-Nielsen, K., Baldi, M., Becker, A., Bichet, A., Blöschl, G., Bouwer, L. M., Brauer, A., Cioffi, F., Delgado, J. M., Gocht, M., Guzzetti, F., Harrigan, S., Hirschboeck, K., Kilsby, C., Kron, W., Kwon, H. H., Lall, U., Merz, R., Nissen, K., Salvatti, P., Swierczynski, T., Ulbrich, U., Viglione, A., Ward, P. J., Weiler, M., Wilhelm, B., and Nied, M.: Floods and climate: emerging perspectives for flood risk assessment and management, Nat. Hazards Earth Syst. Sci., 14, 19211942, doi:10.5194/nhess-14-1921-2014, 2014.

Miller, A., Jonkman, S. N., and Van Ledden, M.: Risk to life due to flooding in post-Katrina New Orleans, Nat. Hazards Earth Syst. Sci., 15, 59-73, doi:10.5194/nhess-15-59-2015, 2015.

Milly, P. C. D., Wetherald, R. T., Dunne, K. A., and Delworth, T. L.: Increasing risk of great floods in a changing climate, Nature, 415, 514-517, 2002.

Min, S.-K., Zhang, X., Zwiers, F. W., and Hegerl, G. C.: Human contribution to more-intense precipitation extremes, Nature, 470 , 378-381, 2011.

Mokrech, M., Kebede, A. S., Nicholls, R. J., Wimmer, F., and Feyen, L.: An integrated approach for assessing flood impacts due to future climate and socio-economic conditions and the scope of adaptation in Europe, Climatic Change, 128, 245-260, doi:10.1007/s10584-014-1298-6, 2015.

Munich Re: Munich Reinsurance Company Geo Risks Research: NatCatSERVICE Database, 2013.

Nicholls, R. J.: Coastal flooding and wetland loss in the 21st century: changes under the SRES climate and socioeconomic scenarios, Global Environ. Change, 14, 69-86, doi:10.1016/j.gloenvcha.2003.10.007, 2004.

Nicholls, R. J., Hanson, S., Herweijer, C., Patmore, N., Hallegatte, S., Corfee-Morlot, J., Château, J., and Muir-Wood, R.: Ranking Port Cities with High Exposure and Vulnerability to Climate Extremes: Exposure Estimates, OECD Publishing, 63 pp., doi:10.1787/011766488208, 2008.

Pappenberger, F., Dutra, E., Wetterhall, F., and Cloke, H. L.: Deriving global flood hazard maps of fluvial floods through a physical model cascade, Hydrol. Earth Syst. Sci., 16, 4143-4156, doi:10.5194/hess-16-4143-2012, 2012. 
PBL: Netherlands Environmental Assessment Agency: Towards a world of cities in 2050. An outlook on water-related challenges, Background report to the UN-Habitat Global Report, PBL Netherlands Environmental Assessment Agency PBL, The Hague, 76 pp., 2014.

Risk \& Policy Analysts Limited: Flood defence standards for designated sites, English Nature Research Reports, No. 629, 124 pp., 2006.

Rojas, R., Feyen, L., Bianchi, A., and Dosio, A.: Assessment of future flood hazard in Europe using a large ensemble of biascorrected regional climate simulations, J. Geophys. Res.-Atmos., 117, D17109, doi:10.1029/2012JD017461, 2012.

Rojas, R., Feyen, L., and Watkiss, P.: Climate change and river floods in the European Union: Socio-economic consequences and the costs and benefits of adaptation, Global Environ. Change, 23, 1737-1751, doi:10.1016/j.gloenvcha.2013.08.006, 2013.

Sadoff, C. W., Hall, J. W., Grey, D., Aerts, J. C. J. H., Ait-Kadi, M., Brown, C., Cox, A., Dadson, S., Garrick, D., Kelman, J., McCornick, P., Ringler, C., Rosegrant, M., Whittington, D., and Wiberg, D.: Securing Water, Sustaining Growth: Report of the GWP/OECD Task Force on Water Security and Sustainable Growth, University of Oxford, Oxford, UK, 180 pp., 2015.

Sayers, P., Li, Y., Galloway, G., Penning-Rowsell, E., Shen, F., Wen, K., Chen, Y., and Le Quesne, T.: Flood Risk Management: A Strategic Approach, UNESCO, Paris, 202 pp., 2013.

te Linde, A. H., Bubeck, P., Dekkers, J. E. C., de Moel, H., and Aerts, J. C. J. H.: Future flood risk estimates along the river Rhine, Nat. Hazards Earth Syst. Sci., 11, 459-473, doi:10.5194/nhess-11-459-2011, 2011.

van Vuuren, D. P., Lucas, P. L., and Hilderink, H.: Downscaling drivers of global environmental change: Enabling use of global SRES scenarios at the national and grid levels, Global Environ. Change, 17, 114-130, doi:10.1016/j.gloenvcha.2006.04.004, 2007.
Ward, P. J., Jongman, B., Weiland, F. S., Bouwman, A., v. Beek, R., Bierkens, M. F. P., Ligtvoet, W., and Winsemius, H. C.: Assessing flood risk at the global scale: model setup, results, and sensitivity, Environ. Res. Lett., 8, 044019, doi:10.1088/17489326/8/4/044019, 2013.

Ward, P. J., Jongman, B., Kummu, M., Dettinger, M. D., Sperna Weiland, F. C., and Winsemius, H. C.: Strong influence of El Niño Southern Oscillation on flood risk around the world, P. Natl. Acad. Sci. USA, 111, 15659-15664, doi:10.1073/pnas.1409822111, 2014.

Ward, P. J., Jongman, B., Salamon, P., Simpson, A., Bates, P., De Groeve, T., Muis, S., de Perez, E. C., Rudari, R., Trigg, M. A., and Winsemius, H. C.: Usefulness and limitations of global flood risk models, Nat. Clim. Change, 5, 712-715, doi:10.1038/nclimate2742, 2015.

Winsemius, H. C., Van Beek, L. P. H., Jongman, B., Ward, P. J., and Bouwman, A.: A framework for global river flood risk assessments, Hydrol. Earth Syst. Sci., 17, 1871-1892, doi:10.5194/hess-17-1871-2013, 2013.

Winsemius, H. C., Aerts, J. C. J. H., van Beek, L. P. H., Bierkens, M. F. P., Bouwman, A., Jongman, B., Kwadijk, J. C. J., Ligtvoet, W., Lucas, P. L., van Vuuren, D. P., and Ward, P. J.: Global drivers of future river flood risk, Nat. Clim. Change, 6, 381-385, doi:10.1038/nclimate2893, 2016.

Zurich: Risk Nexus, Central European floods 2013: a retrospective, ${ }^{\circ}$ Zurich Insurance Company Ltd., Zurich, 68 pp., 2014. 